\title{
Comparative Efficacy of Three Bait Toxicants Against the Subterranean Termite Reticulitermes Santonensis (Isoptera: Rhinotermitidae)
}

\author{
Khalid Z Rasib* and D J Wright \\ Department of Biological Sciences, Imperial College of Science Technology and Medicine Silwood, UK
}

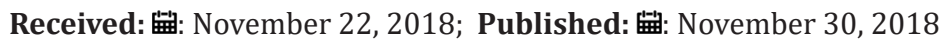

*Corresponding author: Khalid Z Rasib, Department of Biological Sciences, Imperial College of Science Technology and Medicine Silwood, Park London, UK

\section{Opinion}

The study was aimed to provide data to assess the risk poses by termites being able to establish and multiply in the UK. This risk can be judged by determining the minimum number of individuals and biotic and abiotic conditions required for establishment of a termite colony. Workers of $R$. santonensis were used to determine the minimum colony size that can be established in order to produce mini colonies under laboratory conditions. Survival was observed for initial termite number as low as ten under constant conditions at $25{ }^{\circ} \mathrm{C}, 75 \%$ relative humidity over 28 weeks. Results showed that an initial termite number of 250 gave the greatest population survival. Increasing initial termite numbers caused a decrease in the survival in the laboratory. Survival decreased with time in the laboratory trials. Workers of Reticulitermes santonensis were also baited with three commercially available insecticides to test their efficacy at different concentrations using treated bait matrix as Whatmann\# 1 filter paper to document the suppression and complete mortality.

Response of the subterranean termite $R$. santonensis (Isoptera: Rhinotermitidae) to three bait toxicants, Imodacloprid, Thiamethoxam, and hexaflumuron, was evaluated. The results showed that during the 3-weeks test period, all termites were killed by Hexaflumuron at $1000 \mathrm{ppm}$, Thiamethoxam at 100ppm and Imidacloprid at $300 \mathrm{ppm}$. As these insecticides are environmentally safe, adequately stable and non- repellent, so termites will take it up while feeding on the treated baits. Being 'slow-acting' (with postponed action), the effects of the termiticides are manifested only after termites have carried it back to the nest and distributed it among nest mates during mutual food exchange through stomodial and proctodial trophallaxis activities. The horizontal transfer of lethal effects of slow acting non repellent termiticides can fulfil the requirements of a liquid bait model for their potential to termite control methods. The termite baiting system technologies are particularly appealing to those concerned with the potential risks associated with the large quantities of liquid termiticides necessary for the traditional chemical barrier treatments for termites' control. Choice and no-choice feeding bioassays using treated filter papers with bait toxicants (Thiamethoxam and Hexaflumuron) were also conducted to determine the consumption and mortality of Reticulitermes santonensis termite in the laboratory.

Control filter paper in no-choice and choice tests using distilled water as solvent was also evaluated. In choice bioassays, $R$. santonensis workers preferred to feed on untreated filter paper rather than filter paper treated with Hexaflumuron and Thiamethoxam bait toxicants. In general, termite workers consumed more control paper than the treated paper. In case of Thiamethoxam bioassays, termite workers showed more feeding on control $(322.0 \mathrm{mg})$ than the Thiamethoxam treated paper $80.0,108,125.0,164.0,192.0 \mathrm{mg}$ at $100,10,2.5,1.0$ and $0.25 \mathrm{ppm}$. In the choice hexaflumuron bioassays, termite workers repeated the instinct and consequently consumed more of the untreated paper than the treated one. The amount of paper consumed was 98.0,120.0,145.0,177.0,198.0mg at $1000,500,200,50$ and $10 \mathrm{ppm}$ respectively. Significantly smaller amounts of the treated filter papers were eaten in comparison with control baits when $R$. santonensis workers were exposed to hexaflumuron and thiamethoxam. The amount of the treated filter paper consumed was significantly different $(\mathrm{P}<0.0001)$ than the amount consumed in the case of untreated at all concentrations tested for the thiamethoxam. This decrease in treated filter paper consumption at higher doses in particular indicate the anti-feedant effects at higher doses in both cases. 
In general, a decrease in termite mortality was recorded in the choice test. In No Choice feeding bioassays, based on the results the percent mortality was greater and more apparent. Comparing the highest doses of each insecticide, Thiamethoxam proved more toxic with $100 \%$ mortality at $100 \mathrm{ppm}$, whereas hexaflumuron at 1000 ppm provoked $90 \%$ mortality of the $R$. santonensis workers.

ISSN: 2574-1241

DOI: $10.26717 / B J S T R .2018 .11 .002125$

Khalid Z Rasib. Biomed J Sci \& Tech Res

CC (i) This work is licensed under Creative

Submission Link: https://biomedres.us/submit-manuscript.php
The use of bait toxicants like hexaflumuron, Thiamethoxam and Imidacloprid in termite baits is briefly discussed. These overall results indicate that Thiamethoxam is effective as a bait toxicant at $100 \mathrm{ppm}$; Imidacloprid at 300ppm and hexaflumuron at 3,000 ppm against $R$. santonensis.

$\begin{array}{ll}\text { BIOMEDICAL } & \text { Assets of Publishing with us } \\ \text { RESEARCHES } & \text { - Global archiving of articles } \\ \text { - Immediate, unrestricted online access }\end{array}$

